\title{
Colposcopic Evaluation of Clinically Unhealthy Cervix
}

\author{
Khaleda Akter ${ }^{1, ~ *, ~ S h a i k h ~ Z i n n a t ~ A r a ~ N a s r e e n ~}{ }^{1}$, Daharul Islam², Sakhawat Hossain ${ }^{2}$ \\ ${ }^{1}$ Department of Gynae \& Obs, Z H Sikder Women's Medical College \& Hospital, Dhaka, Bangladesh \\ ${ }^{2}$ Department of Medicine, Sir Salimullah Medical College \& Mitford Hospital, Dhaka, Bangladesh
}

Email address:

dr.khaleda@gmail.com (K. Akter)

${ }^{*}$ Corresponding author

\section{To cite this article:}

Khaleda Akter, Shaikh Zinnat Ara Nasreen, Md. Daharul Islam, Md. Sakhawat Hossain. Colposcopic Evaluation of Clinically Unhealthy Cervix. Journal of Gynecology and Obstetrics. Vol. 9, No. 4, 2021, pp. 116-119. doi: 10.11648/j.jgo.20210904.14

Received: March 22, 2021; Accepted: April 12, 2021; Published: August 18, 2021

\begin{abstract}
Cervical cancer is the commonest malignancy found amongst Bangladeshi women and the third most common cancer in the world. New cases of invasive cervical cancer are diagnosed over 5,00,000 annually worldwide. For Cervical Intra-Epithelial Neoplasia (CIN) and for invasive cancer of the uterine cervix, Papanicolaou's (Pap) smear is the primary screening tool. The Pap smear accuracy, which was recently assumed found to be $80 \%$ to $95 \%$ for detecting CIN and early invasive cancer, was questioned. Colposcopy and directed biopsy are needed to clarify the clinically unhealthy cervix in women. This study was conducted to evaluate the role of colposcopy in identifying. The aim of the study was to assess the role of colposcopy of the unhealthy cervix to localize the lesions and to obtain biopsies from the selected areas. This prospective observational study conducted from January 2016 to December 2016 in the Department of Obstetrics and Gynaecology, Sikder Medical College, Dhaka including 104 patients who were aged between 25-65 years with clinically unhealthy cervix, were exposed to a colposcopic evaluation. All the patients underwent colposcopic-directed biopsies. The biopsies were taken from the act white areas and the iodine negative areas. Among 104 patients, 49 (47.1\%) were in the age group of 25-34 years. In the parity, 97 (93.3\%) 0-4 child, 61 (58.7\%) were married before 18 years of age. 17 (16.35\%) had normal colposcopic findings. The colposcopic evaluation and the guided biopsy were successful in detecting abnormalities in 26 out of 31 cases. The incidence of CIN 1 and CIN2, 3 were found colposcopically and histologically $33.65 \%, 24.04 \%$, and $11.54 \%$, respectively. In the present study, the sensitivity of colposcopy was $83.33 \%$. Both the neoplastic and the non-neo-plastic ones, colposcopy was found to be useful in understanding the morphology of the cervical lesions and this would very helpful in planning their management in the future.
\end{abstract}

Keywords: Cancer, Colposcopy, Cervical, Cervix, Invasive, CIN, Unhealthy, Biopsies

\section{Introduction}

Cervical cancer continues to be a leading cause of mortality among women in our country, despite the existing prevention programmes. Carcinoma is the most frequent of all the genital tract cancers of the cervix. It is very common for the gynaecologists who work in tertiary care institutes in developing countries to get referrals from practitioners and peripheral health centres for patients with a clinical diagnosis of an "unhealthy cervix." [1] For Cervical Intra-Epithelial Neoplasia (CIN) and invasive cancer of the uterine cervix, Papanicolaou's (Pap) smear is the primary screening tool. The assumed accuracy of the pap smear, which was recently found to be $80 \%$ to $95 \%$ for detecting CIN and early invasive cancer was questioned. Equally, a false negative rate of the Pap smear had been reported under carefully controlled conditions. [2] Screening colposcopy and the simultaneous use of cytological studies has been shown to increase the rate of cervical cancer detection. In order to identify the women who, require treatment, a colposcopic evaluation and a guided biopsy remain a critical diagnostic step for women with squamous intraepithelial lesions. [3] Hence, women with a clinically unhealthy cervix to colposcopy and directed biopsy there is an obvious need. This study was conducted to assess the role of colposcopy in the detection of an unhealthy cervix. Cervical cancer is the second most common cancer in women in India. [4] Invasive cancer of cervix has been considered a preventable cancer because it has a long pre- 
invasive state, cervical cytology screening programs are available and the treatment of pre-invasive lesions is effective. [5] The unique accessibility of the cervix to direct visualization and the possibility of cellular and tissue sampling has permitted extensive investigations on lesions of cervix. There are various methods available for screening of cervical precancerous and cancerous lesions like visual inspection by acetic acid (VIA), Visual inspection by Lugol's Iodine (VILI), conventional pap smear, liquid based cytology, colposcopy and HPV (Human Papilloma Virus) DNA testing. $[6,7]$ But, the naked eye evaluation of unhealthy cervix is deceptive sometimes and so is the cytology as negative cytology does not rule out cervical intraepithelial lesions (CIN) completely. Unhealthy cervix and abnormal pap smears need further evaluation and confirmation by colposcopy and colposcopic directed punch biopsy of cervical lesions. [8] Screening of the cervix by cytology and colposcopy can significantly reduce the cases of invasive cancers. [2, 9]

\section{Aims of the Study}

The aim of the study was to assess the role of colposcopy of the unhealthy cervix to localize the lesions and to obtain biopsies from the selected areas.

\section{Materials and Methods}

This was a prospective clinical study on the women who attended the Gynaecology Outpatients Department at Sikder Medical College Hospital from January 2012 to December 2012. The institutional ethical committee clearance was obtained and informed consent was taken from all the study subjects. Total 104 patients aged between 25-65 years with the clinically unhealthy cervix, were bare to a colposcopic evaluation. Before colposcopic directed biopsies, all patients underwent both the acetic acid and the Schiller's test. The biopsies were done from the acetowhite areas and the iodine negative areas of women with open cervical lesions and bleeding. Findings were categorized in acetowhite epithelium, abnormal vascular patterns, and negative schillers iodine test.

\section{Results}

Out of the 104 patients, $49(47.1 \%)$ were in the age group of $25-34$ years. $97(93.3 \%)$ were in the parity group $0-4.61(58.7 \%)$ were married before they were 18 years of age. The major presenting complaints among the study patients were a white discharge per vagina 53 (50.96\%), lower abdominal pain $21(20.19 \%)$, and post coital bleeding $7(6.73 \%)$. Out of the 104 patients, $17(16.35 \%)$ had normal colposcopy findings, $22(21.15 \%)$ patients had inflammation, $35(33.65 \%)$ patients had CIN1 and 25 (24.04\%) had CIN2, 3. The findings on colposcopy were acetowhite areas, punctuation, mosaic pattern, abnormal vasculature and normal which were $44.23 \%, 25 \%, 9.62 \%$, $4.80 \%$ and $16.35 \%$ respectively. On biopsy, cervicitis was most commonly found $53(50.96 \%)$, maximum in age group 25-34 years 24 (23.07\%). The colposcopic evaluation and the guided biopsy were successful in detecting abnormalities in 26 out of 31 cases. Colposcopy failed to diagnose abnormalities in 5 cases, which were diagnosed histologically.

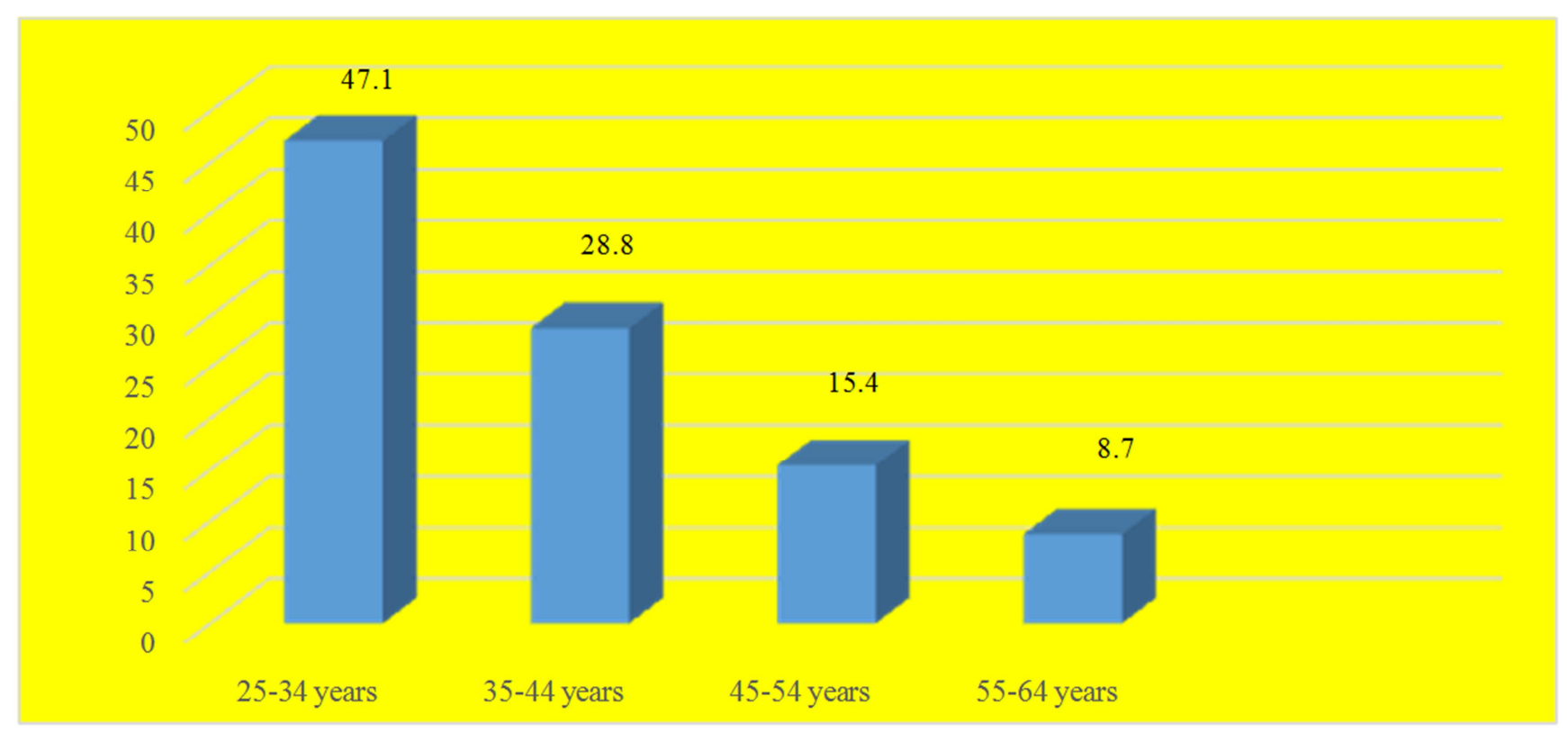

Figure 1. Participants Age Groups. 


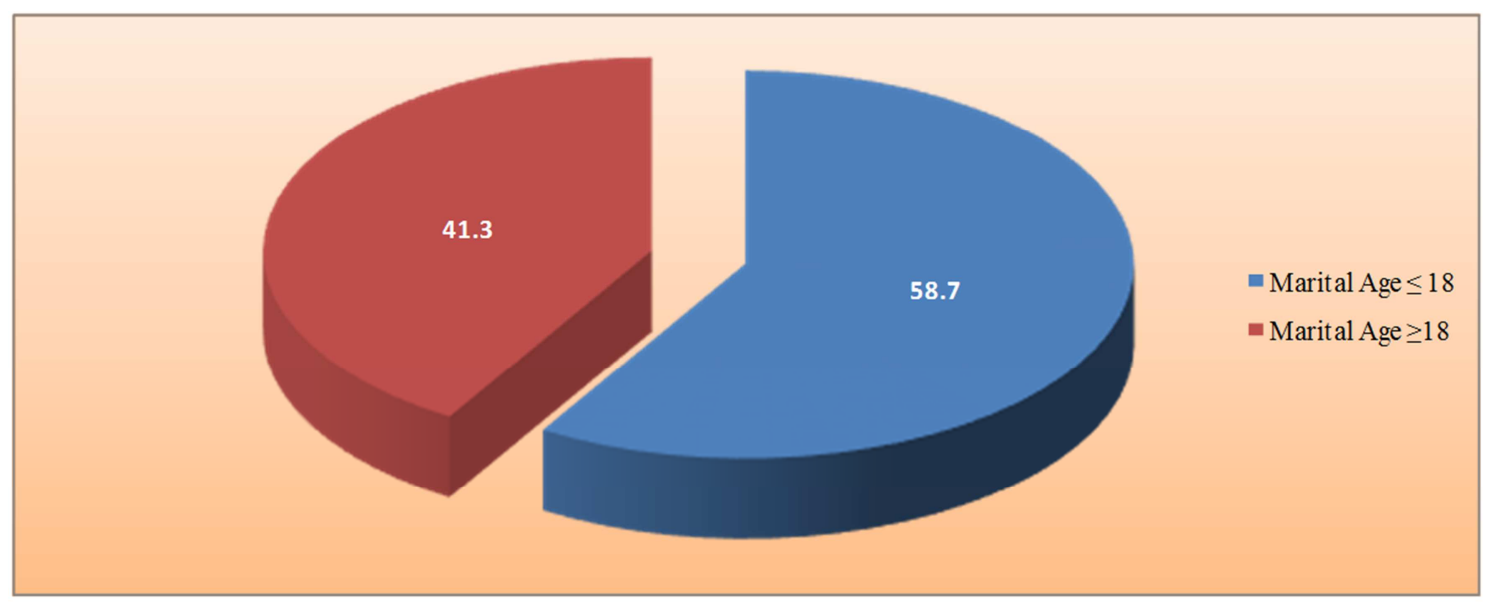

Figure 2. Participants Marital Age.

Table 1. Baseline characteristics of the study population.

\begin{tabular}{lll}
\hline Baseline characteristics & Frequency (n) & Percentage (\%) \\
\hline Age (years) & & \\
$25-34$ & 49 & 47.1 \\
$35-44$ & 30 & 28.8 \\
$45-54$ & 16 & 15.4 \\
$55-64$ & 9 & 8.7 \\
Parity & & \\
Primi & 7 & 6.7 \\
Multi & 97 & 93.3 \\
Marital age & & \\
$\leq 18$ years & 61 & 58.7 \\
$>18$ years & 43 & 41.3 \\
\hline
\end{tabular}

Table 2. Shows major presenting complaints.

\begin{tabular}{ll}
\hline Symptoms & n (\%) \\
\hline White discharge per vagina & $53(50.96 \%)$ \\
Irregular menstruation & $18(17.31 \%)$ \\
Lower abdomen/back pain & $21(20.19 \%)$ \\
Post-menopausal bleeding & $5(4.81 \%)$ \\
Post coital bleeding & $7(6.73 \%)$ \\
\hline
\end{tabular}

Table 3. Shows colposcopy findings ( $n=104)$ of clinically unhealthy cervix.

\begin{tabular}{lll}
\hline Findings & Number of cases & Percentage (\%) \\
\hline Normal & 17 & 16.35 \\
Inflammation & 22 & 21.15 \\
CIN1 & 35 & 33.65 \\
CIN2, 3 & 25 & 24.04 \\
Suspect invasive cancer & 5 & 4.81 \\
Base & 104 & 100.0 \\
\hline
\end{tabular}

Table 4. Shows abnormal colposcopy findings $(n=104)$.

\begin{tabular}{lll}
\hline Finding & Number of cases & Percentage (\%) \\
\hline Acetowhite areas & 46 & 44.23 \\
Punctuations & 26 & 25 \\
Mosaic pattern & 10 & 9.62 \\
Abnormal vasculature & 5 & 4.80 \\
Normal & 17 & 16.35 \\
\hline
\end{tabular}

Table 5. Shows biopsy report of the study patients in relation to age of the patients.

\begin{tabular}{|c|c|c|c|c|c|c|}
\hline Age (Years) & Cervicitis & Mild Dysplasia & Moderate Dysplasia & Severe Dysplasia & Carcinoma in Situ & Normal \\
\hline $25-34(\mathrm{~N}=49)$ & 24 & 3 & 1 & 2 & 0 & 19 \\
\hline $35-44(\mathrm{~N}=30)$ & 15 & 6 & 4 & 3 & 2 & 0 \\
\hline $45-54(\mathrm{~N}=16)$ & 9 & 2 & 2 & 1 & 1 & 1 \\
\hline $55-64(\mathrm{~N}=9)$ & 5 & 1 & 1 & 1 & 1 & 0 \\
\hline Base N (104) & $\mathrm{n}=53(50.96 \%)$ & $\mathrm{n}=12(11.54 \%)$ & $\mathrm{n}=8(7.69 \%)$ & $\mathrm{n}=7(6.73 \%)$ & $\mathrm{n}=4(3.85 \%)$ & $\mathrm{n}=20(19.23 \%)$ \\
\hline
\end{tabular}

Table 6. Showing analysis of the results.

\begin{tabular}{lllll}
\hline Biopsy & & & & \\
\hline & & Positive & Negative & Total \\
\hline \multirow{2}{*}{ Colposcopy } & Positive & 26 & 39 & 65 \\
Base & Negative & 5 & 34 & 39 \\
\hline
\end{tabular}

Table 7. Diagnostic test.

\begin{tabular}{lll}
\hline Statistic & Value & $\mathbf{9 5 \%}$ CI \\
\hline Sensitivity & $83.33 \%$ & $62.62 \%$ to $95.26 \%$ \\
Specificity & $46.43 \%$ & $32.99 \%$ to $60.26 \%$ \\
Positive Predictive Value & $40.00 \%$ & $33.01 \%$ to $47.43 \%$ \\
Negative Predictive Value & $86.67 \%$ & $71.79 \%$ to $94.32 \%$ \\
Accuracy & $57.50 \%$ & $45.94 \%$ to $68.49 \%$ \\
\hline
\end{tabular}

The sensitivity and the specificity of colposcopy were $83.33 \%$ and $46.42 \%$ respectively. The positive predictive value and the negative predictive value of colposcopy in the present study were $40 \%$ and $86.67 \%$ respectively.

\section{Discussions}

Cervical cancer has an uneven geographic distribution with the majority of cases being in developing countries. Declining trends in the developed countries over the last few decades are attributed to the implementation of organized screening programs by Pap smear. Colposcopy is an excellent means of evaluating a clinical method of proven accuracy for 
the clinically unhealthy cervix. The most common colposcopic findings in our study were the aceotowhite areas in $44.23 \%$ of the women, as compared to the study of Zivadinovic et al. [10], where the most common colposcopic finding was the mosaic pattern, which was seen in $44 \%$ of the women. In a study of Rokita [11], the presence of acetowhite epithelium, very white or gray opaque epithelium, flat mosaic, coarse mosaic, flat and coarse leukoplakia, coarse punctuation, and the atypical vessels correlated with the atypical transformation zone. In this study, the evaluation of the women who presented with postcoital bleeding by cytology and colposcopy by Afsaneh Tehranian [12] the sensitivity of colposcopy is reported to be $79 \%$. In a study by Kavanagh, this pattern of cytosmear and colposcopy use within the Canberra territory $44 \%$ of young women had undergone Pap smear examinations and that $2.5 \%$ had undergone colposcopy. [13] Detection of high-grade CIN and intrinsic to vivo tissues, recent technological advancements of fluorescence, reflectance, and spectroscopy have led to the development of a useful adjunct to improve the colposcopic detection of high-grade CIN and intrinsic to the in vivo tissues. [14] Until better strategies are developed in order to find CIN2+ in women with borderline changes, the biopsies of all the acetowhite lesions will yield the greatest sensitivity for detecting cervical precancer. [15] The earlier diagnosis of invasive cervical cancer and CIN in adult women is a desirable goal. Hence, a conservative line of management can be chosen, especially in young women, a colposcopic evaluation of an unhealthy cervix is necessary for the earlier detection of premalignant lesions of the cervix.

\section{Conclusions}

Colposcopy was found the morphology of the cervical lesions, both of the neoplastic and the non-neo-plastic ones. The low sensitivity, false negative and the poor compliance for follow-up, cytology is an accepted method for screening for cervical neoplasia. The value of colposcopy has been recognized, mainly in the evaluation of patients with abnormal cervical smears. So, it has been felt that colposcopy should be offered as a diagnostic method in all patients with unhealthy cervix apart from cervical smear evaluation. For the detection of preneoplastic and early cervical cancer, a detailed colposcopic evaluation of the cervix with a guided biopsy is an important diagnostic method.

\section{References}

[1] Dasari P. A grossly abnormal cervix: Evidence for using colposcopy in the absence of a squamous intraepithelial lesion by the conventional Papanicolau's test. Journal of Gynecologic Surgery. 2011 March; 27 (1).
[2] Singh SL, Dastur NA, Nanavat MS. A comparision of colposcopy and the Papanicolaou smear: sensitivity, specificity and predictive value. Bombay Hospital Journal. 2000 July; 42 (3).

[3] Pimple SA, Amin G, Goswami S, Shastri SS. Evaluation of colposcopy vs cytology as a secondary test in triage women was found to be positive on the visual inspection tests. Indian J Cancer. 2010 Jul-Sep; 47 (3): 308-13.

[4] Arnold M, Soerjomataram I, Ferlay J, Forman D. Global incidence of oesophageal cancer by histological subtype in 2012. Gut. 2015 Mar 1; 64 (3): 381-7.

[5] Sankaranarayanan R, Nene BM, Dinshaw K, Rajkumar R, Shastri S, Wesley R, Basu P, Sharma R, Thara S, Budukh A, Parkin DM. Early detection of cervical cancer with visual inspection methods: a summary of completed and on-going studies in India. salud pública de méxico. 2003; 45 (S3): 309407.

[6] Dabash R, Vajpayee J, Jacob M, Dzuba I, Lal N, Bradley J, Prasad LB. A strategic assessment of cervical cancer prevention and treatment services in 3 districts of Uttar Pradesh, India. Reproductive health. 2005 Dec; 2 (1): 1-8.

[7] World Health Organization. New WHO guide to prevent and control cervical cancer. 2014.

[8] Shobha T, Davuluri S. Cervicalcytopathology: evaluation of its efficacy in detecting cervical precancerous and cancerous lesions, as evidenced by colposcopic biopsy. Int J Sci Res 2016; 5 (5).

[9] Arora R, Vijaya K, Habeebullah S, Asha O. Colposcopic evaluation of unhealthy cervix. J Obstet Gynecol Ind. 2000; 50: $102-3$.

[10] Zivadinovic R, RadovicM, Lili V, Petric S. Grading the severity of the preinvasive changes of the uterine cervix by colposcopy and exfoliating cytology. Medicine and Biology. 2005; 12 (1): 55-59.

[11] Rokita W. Colposcopy of the abnormal transformation zone. Wiadomosci Lekarskie. 2006; 59 (7-8): 486-89.

[12] Tehranian A, Rezaii N, Mitra M, Eslami B, Arab M, Asgari Z. Evaluation of the women who present with postcoital bleeding, by cytology and colposcopy. International Journal of Gynecology and Obstetrics. 2009 April; 105 (1): 18-20.

[13] Kavanagh AM, Santow G, Mitchell H. Consequences of the current patterns of the Pap smear and colposcopy use. J Med Screen. 1996; 3 (1): 29-34.

[14] Kendrick JE, Huh WK, Alvarez RD. Device Profile: the LUMA $^{\mathrm{TM}}$ Cervical Imaging System. Expert Review of Medical Devices. 2007 March; 4 (2): 121-29.

[15] Massad LS, Jeronimo J, Katki HA, Schiffman M. The accuracy of the colposcopic grading for the detection of highgrade cervical intra-epithelial neoplasia. J Low Genit Tract Dis. 2009 Jul; 13 (3): 137-44. 